\title{
SHALLOW OHMIC CONTACT SYSTEM TO $n$-GaAs
}

\author{
E. Kamińska, A. Piotrowska, T.T. Piotrowski, A. Barcz, \\ M. Guziewicz, J. AdAMCZEWSKa \\ Institute of Electron Technology, Al. Lotników 32/46, 02-668 Warszawa, Poland
}

\section{AND S. KWIATKOWSKI}

Institute of Nuclear Studies, Hoża 69, 00-682 Warszawa, Poland

Low resistance $(\mathrm{Au}) \mathrm{GeNi}$ ohmic contacts to $n$-GaAs with smooth morphology and restricted penetration into the substrate have been fabricated. Rapid thermally nitrided tungsten has been demonstrated to be an effective capping layer during the contact processing.

PACS numbers: $73.40 . \mathrm{Ns}$

The penetration of metallization during the formation of ohmic contacts to semiconductor microstructures is one of the most important factors presently limiting the minimum useful size of modern GaAs devices. Consequently, much attention has been recently devoted to the development of shallow ohmic contact systems. Since the first study on the use of AuGeNi metallization [1] it has been still difficult to find a better candidate for ohmic contact to $n$-GaAs. Thus, a great deal of efforts was aimed to improve the control of the penetration depth, the uniformity of the interface and the surface morphology of this contact [2]. Recently, low-Au content $(\mathrm{Au}) \mathrm{GeNi} / \mathrm{W}$ ohmic contacts have been proposed [3]. In this paper we report on the use of $(\mathrm{Au}) \mathrm{GeNi} / \mathrm{W}$ metallization with the reduced amount of $\mathrm{Au}$ and its further processing by rapid thermal nitridation. Nitrided tungsten has been expected to serve as a cup suppressing the sublimation of As which is the main driving force for thin film Au-GaAs reaction, and thus reducing the decomposition of semiconductor substrate and the penetration of metallization components.

Contacts were fabricated on (100) $n$-GaAs bulk doped with Si at $10^{18} \mathrm{~cm}^{-3}$. Prior to the deposition of metallization, the samples were processed in hot organic solvents and etched in $\mathrm{NH}_{4} \mathrm{OH}+\mathrm{H}_{2} \mathrm{O}_{2}+\mathrm{H}_{2} \mathrm{O}$ solution. $70 \mathrm{~nm}$ thick $(\mathrm{Au}) \mathrm{GeNi}$ metallization consisting of 10 at.\% Au, 45 at.\%Ge and $45 \mathrm{at} . \% \mathrm{Ni}$ was thermally evaporated from the resistance-heated crucible. The top tungsten layer of a thickness of $40 \mathrm{~nm}$ was deposited by DC magnetron sputtering. To study the effect of annealing conditions on the effectiveness of $\mathrm{W}$ cap, comparative experiments involving conventional heat treatment under flowing $\mathrm{H}_{2}$ and rapid thermal annealings in SHS-100 system, in $\mathrm{N}_{2}$ or $\mathrm{O}_{2}$ ambient, have been performed. 
Optical microscopy with Nomarski contrast, secondary-ion-mass spectroscopy (SIMS), Rutherford backscattering spectroscopy (RBS), and X-ray diffraction (XRD) have been applied to investigate contact microstructures. Electrical characterization involved the measurements of the specific contact resistance by four-point method.

The net result of these experiments is that conventional annealing produces $\mathrm{AuGeNi} / \mathrm{W}$ contacts with the minimum specific contact resistance of $8.5 \times 10^{-5} \Omega \mathrm{cm}^{2}$ for $T=400^{\circ} \mathrm{C}, t=3 \mathrm{~min}$. The results of rapid thermal processing strongly depend on the annealing atmosphere. Contacts formed in nitrogen exhibited the lowest $r_{c}=3 \times 10^{-5} \Omega \mathrm{cm}^{2}$ after annealing at $500-600^{\circ} \mathrm{C}$ for 15 sec. In contrast, contacts heat treated in oxygen at temperatures below $500^{\circ} \mathrm{C}$ preserved rectifying properties, while annealed above $500^{\circ} \mathrm{C}$ became entirely nonconducting.

Metallurgical studies give evidence that the microstructure of the contacts developing during thermal processing is responsible for the properties of $n$-GaAs/(Au)GeNi/W contacts. XRD analysis proves that oxygen exposure produces tungsten oxide $\mathrm{WO}_{3}$, which explains insulating properties of rapid thermally oxidized contacts.
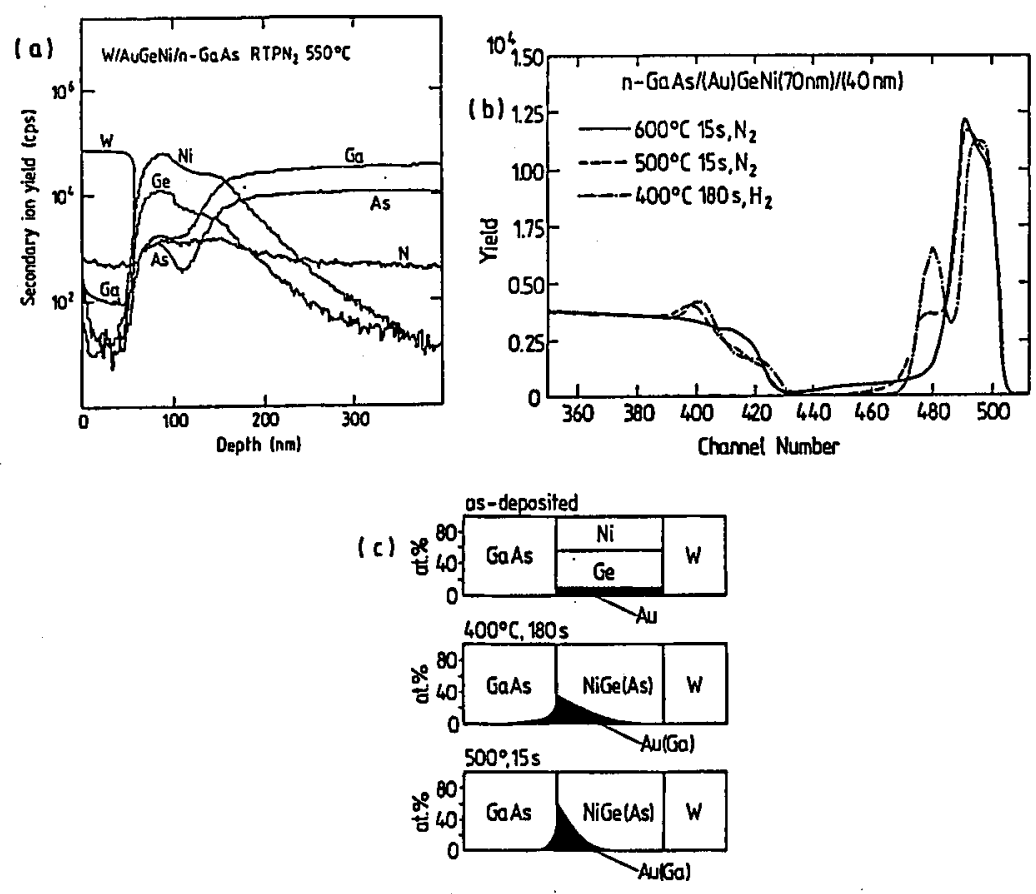

Fig. 1. Microstructure of $n-\mathrm{GaAs} /(\mathrm{Au}) \mathrm{GeNi} / \mathrm{W}$ contacts: (a) SIMS depth profile of rapid thermally nitrided contact, (b) RBS spectra of $\mathrm{H}_{2}$ annealed and rapid thermal processing $\mathrm{N}_{2}$ annealed contacts, (c) schematic illustration of the microstructure of $\mathrm{H}_{2}$ and $\mathrm{N}_{2}$ processed contacts. 
Figure 1a shows SIMS depth profiles of the $550^{\circ} \mathrm{C} \mathrm{N}$ annealed contact (Au is not shown). Near the $\mathrm{W} /(\mathrm{Au}) \mathrm{GeNi}$ interface a noticeable accumulation of $\mathrm{Ni}$, $\mathrm{Ge}$ and As is observed. The RBS spectra from contacts annealed in a conventional system and rapid thermally nitrided, were analysed using RUMP simulation program (Fig. 1b). A significant reduction in height in low-energy part of the spectrum from the hydrogen annealed sample is indicative of an enhanced indiffusion of $\mathrm{Au}$ into GaAs. The penetration of Au into semiconductor substrate is much smaller in the case of contacts processed in nitrogen. In both cases an accumulation of $\mathrm{Ni}$ and $\mathrm{Ge}$ at $\mathrm{W} /(\mathrm{Au}) \mathrm{GeNi}$ interface is observed. Rapid thermal annealing at $600^{\circ} \mathrm{C}$ produced an intermixing of all contact constituents. No changes in the structure of the tungsten capping layer after annealing in $\mathrm{N}_{2}$ up to $600^{\circ} \mathrm{C}$ were detected by XRD analysis. Figure 1c shows a schematic presentation of metallurgical transformations occurring in both types of contacts as a result of heat treatment.

Following the annealing, samples were etched to remove selectively the metallization. The GaAs surface morphology was examined by optical microscopy with Nomarski contrast. The interface of conventionally annealed contact was pitted which is characteristic of local interaction of metallization with the substrate. In contrast, those processed in $\mathrm{N}_{2}$ ambient exhibited sparse or no features. The surface of nitrided contacts remained almost unchanged after heat treatment.

Concluding, the fabrication of low resistance ohmic contacts to $n$-GaAs with smooth morphology and restricted depth of penetration has been demonstrated. The presented results prove the effectiveness of nitrided tungsten capping layer in suppressing the decomposition of GaAs during the thermal processing of contact. The properties of nitrided tungsten are probably related with the stuffing the grain boundaries with nitrogen [4].

\section{References}

[1] N. Braslau, J.B. Gunn, J.L. Staples, Solid-State Electron. 10, 381 (1967).

[2] Yih-Cheng Shih, M. Murakami, E.L. Wilkie, A.C. Callegari, J. Appl. Phys. 62, 582 (1987).

[3] N. Lustig, M. Murakami, M. Norcott, K. McGann, Appl. Phys. Lett. 58, 2093 (1991).

[4] M.-A. Nicolet, M. Bartur, J. Vac. Sci. Technol. 19, 786 (1981). 